\title{
A WHOLE NEW WORLD: Measuring Teacher Candidate Dispositions through Cultural Immersion and Service Learning
}

\author{
Rachel B. Dunbar, PhD \\ Jodie Winship, PhD \\ Sallie Harper, PhD
}

The University of West Alabama, United States

URL:http://dx.doi.org/10.19044/ejes.s.v6a3

\begin{abstract}
When teachers believe in their own ability to teach, they are more likely to provide better instruction for their students. It is not uncommon for new teachers to doubt themselves in the classroom. Not only do teachers have to show a level of confidence, they must also display particular dispositions in their work. "Dispositions" is a term that is often juxtaposed with knowledge and skills (Choi, Benson, \& Shadak, 2016). NCATE (2008) defines dispositions as "professional attitudes, values, and beliefs demonstrated through both verbal and nonverbal behaviors as educators interact with students, families, colleagues, and communities" (p. 89). One has to wonder if these dispositions have any correlation with how teachers will interact with their students. The researchers in this study sought to determine what impact service learning through a cultural immersion experience would have on preservice teachers' dispositions towards students from diverse ethical, cultural and socio-economic backgrounds, especially when poverty is involved. The researchers sought funding from their university to take pre-service teachers in the Department of Teaching and Learning to a facility designed to train groups in appropriate technology for specific third world countries around the world. Pre-service teachers lived in traditional houses, took on traditional roles, learned about commerce through bartering and trading, as well as experienced poverty in a simulated environment. By engaging pre-service teachers in service learning, the researchers hoped to gain insight into how exposure to different cultural environments may impact teacher candidates' dispositions and thoughts toward poverty.
\end{abstract}

Keywords: Trauma, dispositions, empathy, preservice teachers, service, learning. 


\section{Information:}

The dispositions that teachers have towards their students can have a direct impact on the students' learning. Teachers who are not aware of their students' backgrounds or personal circumstances often find it difficult to connect with them in the classroom. Instructors must include tolerance, empathy, and commitment to the field of dispositions pre-service teachers should have (Karges-Bone \& Griffin, 2009). Individuals who are trying to navigate first year teacher education programs and their first years in the classroom can become overwhelmed and frustrated (Osler \& Russell, 2013). They need training and support to help them in their transition to becoming full time educators. One possible way to guide pre-service teachers (hereafter referred to as teacher candidates) in the right direction is to have them engage in cultural immersion through service learning. In service learning pedagogy, Marchel and Shields (2011) explain that there is the drive to have "increased field experiences and the design elements for addressing the dispositions necessary for teachers (p. 2). It is possible for teacher candidates to be impacted, even minimally, in their attitudes and beliefs.

\section{Review of Literature:}

Generally, trauma would be considered a physical or psychological injury that a person experiences at some point in his or her life. This injury cannot necessarily be quantified by others, as the depth of pain that the individual feels is strictly personal. In the past, there was an individualized approach to how victims of trauma were treated (Gutierrez \& Guiterrez, 2019). That has changed over the years to include identification of and support from family members and outside agencies. Just as there are victims of physical trauma, there are victims of cultural trauma as well. According to Phipps and Thorne (2019), students of color have faced cultural trauma for many years. This is a result of a history and social inequities. Cultural trauma is very specific and is directly related to how individuals process information and behave when forced to recall certain situations. Jamili and Roshanzamir (2017) state that if members of a group are traumatized, the trauma becomes "cultural trauma" or "collective trauma" (p.114). When this cultural trauma is coupled with marginalization, the overall impact is compounded.

When it comes to children that experience trauma, teachers must know how to best work with issues related to grief and anxiety. Teachers will not automatically go to school equipped to deal with each issue that confronts them. When they interact with students who have experienced an adverse situation, teachers must be prepared to handle the students appropriately. Honsinger and Brown (2019) posit that teachers must be trained to be traumasensitive as they enter their classrooms. This concept is centered on the idea that teachers should develop "an awareness and understanding of the impact 
of trauma on the lives of children" (p.144). In doing so, teachers can implement strategies that are more effective than traditional methods in the classroom to support learning. Likewise, trauma-informed teachers are those who understand their role as part of a support system for students. They are able to create environments that maintain healthy boundaries, build classroom connections, and serve as a bridge for appropriate support services (Venet, 2019). Teachers who are trauma-sensitive and aware of how trauma impacts students, have clarity on what their role is in the lives of these students.

Having this understanding includes not only awareness and sympathy, but empathy as well. It is not easy to teach a person to be empathetic. It involves three primary components: 1) the ability to take the perspective of another person, 2) the ability to experience what another person feels, and 3) the ability to communicate verbally and non-verbally to the other person that the former understands what the latter is feeling (Bouton, 2016). The term empathy is often used synonymously with sympathy but entails a deeper personal connection. Empathy in a classroom can have a major impact on students. Teachers who are unable to empathize with their students may have more difficulty connecting with them. It is possible for classroom teachers to be empathetic if they are properly trained (Bloom, McNeil, Flasch, \& Sanders, 2018). Teacher preparation programs may have to assume responsibility for making sure that teachers are more sensitive to the personal situations of their students. Leake (2016) offers that empathy can be taught as both rhetoric and as disposition. Naturally, we are prone to feel strongly about those with whom we share the most commonalities and subsequently we have less empathy towards other groups. This results in a trend known as "egoistic drift" (Hoffman, 2001, p. 56). If we make empathy part of our daily practice so that it becomes a natural habit of our mind, it can potentially settle into our personal dispositions (Leake, 2016).

Those dispositions include sensitivity to student needs, improved attitudes towards learning, and heightened awareness of varied cultural and personal differences (Shao \& Tamashiro, 2013). Teachers can have anxiety when working with students from cultural and socioeconomic backgrounds that differ from their own, with the fear that they may not know how to relate to the students (Azano \& Stewart, 2016). This, in turn, has the potential to result in bias towards those groups. Farnsworth and Mackenzie (2015) believe that teacher educator programs must do a better job of training teachers to examine their personal dispositions toward culturally and linguistically diverse groups and seek ways to develop dispositions that reflect empathy, inclusivity, care, and advocacy.

\section{Contribution to Relevant Discipline}

Three faculty members from the University of West Alabama (UWA) requested funding to take teacher candidates from the Department of Teaching 
and Learning on a cultural immersion trip for service learning during the Spring 2019 semester. The purpose of the "field trip" was to determine the extent to which cultural immersion experiences through service learning impact teacher candidates' dispositions. This study was conducted in conjunction with UWA 103: Career Explorations. Given that such a large number of teacher candidates are still "novel" in their understanding of what they fully need to be effective teachers, this research study offered a glimpse into how to help them in their growth as new educators. Teacher education programs have the potential to make adjustments and changes to their curriculum to include a service learning component that speaks towards assisting teacher candidates better develop their personal dispositions as they enter classrooms around the nation. This is most important for teacher candidates who will work with students from diverse ethnic, cultural, and socioeconomic backgrounds. Given that they were at the beginning stages of their program, this was the optimal time to explore where the teacher candidates would be in their thought processes. This study aligned with three out of ten Interstate Teacher Assessment and Support Consortium (INTASC) standards for education: INTASC Standard \#2- Learning Differences, INTASC Standard \#3- Learning Environments, and INTASC Principle \#9: Professional Learning and Ethical Practice.

\section{Background of University}

UWA is a state-supported, coeducational institution of higher learning in Livingston, Alabama. The University values a diverse student enrollment and welcomes students from throughout the United States and from other countries.

UWA has traditionally been known as a Predominantly White Institution (PWI) where the majority of the population is comprised Caucasian students. In recent years, the demographics at UWA have become more diverse with a greater enrollment of minority and international students, causing the university to be considered a Predominantly Black Institution (PBI). This is not to be confused with Historically Black Colleges or Universities (HBCUs) which were originally established to serve the needs of African American students who were not allowed to attend majority institutions.

\section{Description of the Black Belt}

Generally, a county is included in the definition of Alabama's Black Belt region if there is an African American population at or above 50 percent. This high percentage, to some extent, reflects the agricultural plantation system, which influenced $19^{\text {th }}$ century settlement in the region. Many people migrated out of Alabama when the economy begin to decline in the Black Belt, 
which was prompted by farming becoming more mechanical leading to the need for less manual labor. Cotton agriculture declined as well, while coal and steel steadily rose. More and more individuals left the region. Nine out of the 10 poorest counties in Alabama-Barbour, Dallas, Greene, Hale, Lowndes, Macon, Perry, Sumter, and Wilcox - are in the Black Belt. UWA, situated in Sumter County, consistently seeks ways to support economic growth and development in Sumter County and the surrounding areas. This information is significant in relation to this study because of the concentration on impoverished areas.

\section{Methodology}

In order to collect data for this study, the researchers administered surveys to the participants. Surveys can be designed to measure many different outcomes for study participants and are used widely for various purposes. Immekus (2016) posits that the type of survey selected for a study should be in direct alignment with what is being measured. Stating the measure at the onset of a research study decreases the possibility that results are not aligned with the intended results. For this study, the researchers gave volunteer participants a pre-survey that evaluated their current dispositions using a Likert scale. This particular survey was adapted from The Community Action Poverty Simulation Experience (Stout, 2016) and was designed to measure an individual's dispositions related to their thoughts about poverty. The pre and post survey had have the same questions. The post survey included four additional self-reflective open ended questions. The researchers submitted the survey for IRB approval before administering it to participants.

\section{Proposed Study}

The site for this cultural immersion experience through service learning was the Servants in Faith and Technology (SIFAT) campus in Lineville, Alabama. SIFAT is a non-profit organization that trains various groups in community development for impoverished countries around the world. Those who participate in the overnight retreats or day-long activities at SIFAT learn more about global issues, basic needs, scarcity of resources, and disparity. SIFAT staff members use their 176-acre farm as the setting for the daily training that they conduct for school and church groups that visit year round. Participants can experience activities such as living in slum areas, determine ways to survive without adequate resources or technology, and create projects that can be implemented in another country.

For the purpose of this research, the goal was to see what impact, if any, a service learning project would have on teacher candidates and their dispositions towards people from diverse cultural backgrounds who may be in situations of poverty. Participation in the service learning project was 
completely voluntary. Teacher candidates who did not attend were require to interview a teacher candidate who did attend to get feedback on the trip in order to create a trifold brochure with information. Those who attended the trip were committed to staying for a day and a half, fully participate in all activities, and create a reaction video upon their return.

This trip was intended for new students entering the field of education, but was open to students further along in the program if they chose to attend. The teacher candidates from UWA stayed in the Global Village for 22 hours to have a first-hand experience of what life is like in a remote two-thirds world village. Each teacher candidate spent the night in dwellings that were designed by SIFAT's international students. They cooked over an open fire and worked at jobs appropriate to that part of the world as part of their overnight stay. The various houses in the village were representative of those that are in Bolivia, Ecuador, Guatemala, India, the Philippines, Nepal, Nigeria, Liberia, and Uganda. The Global Village Overnight included both breakfast and dinner for all participants. As part of this experience, the teacher candidates also participated in the Grain and Water Challenge that took place in the Global Village. This activity illustrated world hunger and three of its root causes: poverty, war, and unequal distribution of resources. All participants were divided into the countries listed above and were challenged to metaphorically feed their country for a full year.

\section{The Experience:}

Teacher candidates were divided into five countries with seven family members in each group. They initially packed bags with toiletry items and various personal belongings along with snacks during their stay. When they arrived at SIFAT they were each given a potato sack and instructed that they could only take a total of eight items with them. Three of those items could be a sleeping bag, a flashlight and a jacket. They were allowed to select the other items they wanted to include, but they could not bring more than eight. During the day of the trip, it rained non-stop, which made the conditions both wet and chilly. The guide for the trip took the teacher candidates on a hike through the wilderness from the comfort of the dormitories to lead them to the Global Village. In order to get there, teacher candidates had to cross a river using a fallen tree trunk as their "bridge" and a rope as their handle. This proved to be quite cumbersome for the teacher candidates, as they had to navigate their way across the bridge holding their potato sack and not fall into the water due to the slippery conditions.

Once they made it across the bridge, the teacher candidates found themselves at the customs area. This is when they were forced to show their potato sacks to the customs agent and wait for directions, as they were considered refugees in the simulation. The customs agent confiscated 
whatever items he saw fit. Teacher candidates lost their phones, their blankets, their lighters, their pillows, and their snacks. One teacher candidate was in tears after the customs agent confiscated her snacks and proceeded to eat them in front of her. The teacher candidate was close to losing her temper as she shared her concerns with one of the researchers. The researcher reminded the teacher candidate that this was indeed a simulation; the customs agent was only acting and did not know her personally. His acting was to demonstrate how things may be in some countries if foreign visitors attempted to enter without abiding by the guidelines set forth by the host country. Once the teacher candidates made it to the Global Village and were assigned their dwelling places, they received food rations from The United Nations (actors from SIFAT). Each country received different amounts of rations for their dinner: (quinoa, salsa, and cheese) and for their breakfast the next morning (oatmeal and brown sugar). No country received all of any one food item, which meant that in order for everyone in the country to eat, the residents had to ask for resources from other countries.

Drenched from the rain and tired from the mile and a half walk through the wilderness, the teacher candidates had to settle into their homes and prepare to feed their families for the evening. This was difficult for a number of reasons. The first is that the weather conditions left everything in the woods damp. This meant that it was nearly impossible for teacher candidates to start a fire. They required a fire to boil their water from the creek to cook their food and to sterilize it in order to drink. It took residents in the different countries one to two hours to start a fire in their villages. Several teacher candidates resorted to burning their shoelaces and even spare underwear. The second reason that preparing for the evening was difficult is that none of the dwellings had true beds. Teacher candidates had to come up with creative ways to devise where they would sleep. Residents in one country were able to push together three wooden benches for a make-shift cot, while the residents in the other countries had to sleep on the dirt floor of the hut. They were all able to use their sleeping bags, but still found themselves to be quite uncomfortable later that evening. (In one country the residents did not sleep at all. They stayed up all night talking and getting to know each other better. The residents in another country had intermittent sleep after one resident insisted that a scorpion invaded their personal space).

It was not long before the teacher candidates began to grumble about their situations. They were wet and chilly from the rain and did not have a change of clothes (they were not allowed to bring extra items in their potato sacks). Many of them had never seen quinoa before and did not know how to prepare it. With no way to season the quinoa aside from the cheese and salsa and no meat to accompany it, several of the teacher candidates felt that they were unable to eat the meal that they prepared. This left them feeling "hungry" 
for the night. Teacher candidates were afraid of bugs and wild animals during the evening (there was a snake sighting by the creek) and when evening came, it was pitch black outside, aside from the light of the moon. Teacher candidates were able to walk from one country to another with their flashlights, but they were careful as they attempted to navigate the terrain. For many teacher candidates, the trip to the latrine was traumatizing. They had never used an outside toilet before and most certainly not one that was a narrow wooden structure that enclosed a hole in the ground.

The next morning the United Nations woke up everyone at 7:00 am to begin their day. The teacher candidates had to take on traditional roles that would be considered customary for men and women in various countries. Someone had to get dry leaves and kindling to start a morning fire, someone had to get water from the creek, and someone was responsible for breakfast. As was the case the previous day, not all countries had the same quantity of items to prepare their breakfast. Therefore, they had to ration out supplies to make sure that everyone had oats and brown sugar. Teacher candidates with "texture issues" did not eat the oatmeal. Some simply did not know how to prepare it, just as they did with the quinoa. It is important to note that all of the teacher candidates at least tried the quinoa and the oatmeal, and the vast majority of them ate what they prepared. There were only a few outliers that felt they were unable to eat the food.

After breakfast, The United Nations engaged everyone in The Grain and Water Challenge. Each country was given a small bag of grain and a few coins that represented their production and consumption rate. They had to trade with other countries per their trade agreements. It was in this simulation that the teacher candidates demonstrated their survival skills. Countries were meant to barter and trade with each other and most did. However, there were many residents that implemented arbitrary taxes for individuals to cross a bridge to go from one country to another. Residents also inflated trading prices for a cup of grain that was not in the actual trading agreement. Other residents pirated other countries. The country that was most disliked by all of the other countries was the United States, primarily because it was the wealthiest nation.

When the simulation was complete, 22 hours after they first arrived at SIFAT, the teacher candidates were exhausted, dirty, and hungry. They were able to return to the dormitories and take a brief shower. The researchers put out an abundance of snacks for the teacher candidates, enough that everyone could have at least two to three items each, along with a drink. It was interesting that the teacher candidates hesitantly approached the counter to get their snacks and they only took one item at a time, possibly two. Their body language showed their reluctance to take a snack, but they later admitted that they were hesitant because they thought carefully about how their food was rationed the last two days. They did not feel that is was necessary for them to 
rush to get snacks. As the teacher candidates settled to eat their snacks and debrief with the tour guide on their experience, they learned that there were enough resources during the Grain and Water Challenge that no one had to starve in the simulation. This was likened to the fact that there is enough food in the world to go around for everyone and no one has to starve. What people experience every day is simply the harsh reality of the unequal distribution of wealth. There is a great divide between the have and the have nots. Those with limited resources experience the trauma of poverty each day both in the United States and in third world countries. The question is, how does knowing this and seeing the property first hand have an impact on teacher candidates dispositions towards poverty?

\section{Teacher Candidate Responses:}

To answer the above question, the researchers looked at how the teacher candidates responded to the survey when they returned from the trip. The questions on the Likert scale from the survey will be used for a later discussion to provide quantitative data. For the purpose of this discussion from a qualitative perspective, the researchers focused on the responses from two of the four following open-ended questions:

1) The things that I found to be the most challenging during the simulation were (ex. lack of resources such as transportation, education, or other):

2) The changes I would suggest making to improve the poverty simulation experience are:

3) What do you think can be done to address poverty and do you have a new desire (inspired by this experience) to be involved in efforts to address poverty?

4) From the best of your recollection, did you change any answers from pre to post survey? What changes did you make? What aspect of the cultural immersion experience had an impact on your understanding of dispositions? Please be as specific as possible.

Some students admitted that they felt the service learning trip changed them in some way. They saw the experience as not only insightful, but a way to improve their dispositions toward those in poverty. Even though the majority of the PSTs felt the service learning trip had some level of impact on their dispositions, some believed that their ways of thinking were only slightly altered after they returned. They stated that their responses did not change from the pre survey to the post survey. Yet, their extended responses suggested that they were able to walk away with some meaning from the trip. The responses below are direct quotes from Question 3 and Question 4.

*Please note that to maintain the integrity of the responses from the PSTs, the researchers copied the statements verbatim. There are considerable 
grammatical errors, but the researchers did not feel that those took away from the content. As well, there are responses from two Asian students with limited English speaking proficiency. The responses are in no particular order.

Question 3 What do you think can be done to address poverty and do you have a new desire (inspired by this experience) to be involved I efforts to address poverty?

I feel like America should supply other countries more resource[s] to live off of since we have plenty to share.

More help from [the] government.

I do want to be involved in addressing poverty. Since attending SIFAT, I have been very grateful. I have tried not wasting food as a result of the trip. I believe that citizens need to be aware of how bad poverty is before they are willing to help.

Things that can be done to address poverty is to make sure everyone has basic needs and are safe.

I believe that if we all help one another we could help people in poverty. Yes, I do have a new desire.

Ifeel like America is a country who is more well off than other countries. It should help out those other countries because we have the ability to. I learned this from The Grain Game we played. I do have a new desire to be involved in efforts to address poverty.

Mission trips, raising money, food drive, donations of clothing, furniture, food, shoes.

I do have a new desire to address poverty. I felt like an activist after I left.

Some organizations do have clothing drives and raise money for countries that are in poverty. Free health care is provided for the people as well.

Not to complain, not to [be] angry about in this situation in mind. Be positive and calm down to solve the problems with your family members. I know that creating the opportunities in the bad situation is hard, but everything is possible. People need to go out and look around to gain more chances.

Water filter for clean water to use for drinking and bathing.

I have a whole new outlook on poverty. I feel that people who live in poverty need more aid to help in certain situations.

I think that the poverty should be addressed and helped through people wanting to help and give. Yes, because even though we were able to go home most students that you teach cannot get out of it. 
Do a mini poverty simulation on campus. This could be to represent poverty in the United States and how people struggle to buy food, buy clothes, and keep a place to live.

I am inspired to attain a passport and travel out of the country. I hope to study abroad soon.

The experience did make me have a new opinion about poverty. I think America should help people in poverty.

Everything starts small so if schools and communities get together and donate things of need and send to people around the world will be best. I do have a desire to be involved.

In order to address poverty more people should take action to address the issue and provide resources for those people who endure it.

I don't feel like I was taught everything I needed to know to fully grasp the way they lived, but I would address poverty and help any way I can. I have always wanted to help those [who] were less fortunate as I and after this experience, it makes me want to even more.

Create more jobs, create affordable childcare, expand Medicaid.

More jobs, different programs, mentors, and I mainly want to help by providing for the kids that go through these things.

I do not have a desire, but I do have compassion.

We can join the international volunteer team or use our major to serve who need[s] the help. Also, we can donate our pocket money to sponsor a child. Let children have more resources and live and have chance [to] go to school.

Question 4: From the best of your recollection, did you change any answers from pre to post survey? What changes did you make? What aspect of the cultural immersion experience had an impact on your understanding of dispositions? Please be as specific as possible.

Yes. The changes were subtle.

Yes. Chance can let me more understand those country's life. And give me a chance to think what can I do for them. Also, what can I teach my students to know about those countries. Sometimes we cannot change their life but we can help them to be better in the future.

Yes. Understanding and learning more and actually living like people live every day. Realizing how hard it is for certain people and how they have no choice but to live that way really showed me to not take life for granted.

Yes. What I went through, how we had to sleep when we were there. What we had to go through with not knowing how to start a fire or how to cook the food. 
Yes. Not being in poverty, I didn't know how bad it actually was until I had this experience. Complaining about a mattress being worn out is better than sleeping on the ground. Not having a big supply of food, I understood that not everyone has as much of a variety of food like we do. As a future educator you have to understand the possibilities of what a child is experiencing at home or if they even have a home.

Yes. Having an eye-opening experience and being placed in the shoes of others who are not as fortunate as I.

Yes. I realized that I do take a lot for granted in this world and that I should focus more on helping others. I also need to focus on someone's possible background rather than making assumptions based on their looks and actions. I also realized that I don't need to eat a lot to be full. I ate while I was there and was full the majority of the time. Food is a luxury and I need to learn how to appreciate it more.

Yes. This had an impact on me because of the challenges we had to face as a team with limited resources. This helped me understand because I experience [d] the challenges first-hand and realized how hard my life would be if that was my life.

Yes. I learned that no matter what is going on in your life, whether good or bad, you should always remain with a positive attitude because it can have an effect on those around you.

Yes. I realized that I am very privileged and I will no longer take things for granted. I will do more to help my community and love all that are around.

Yes. I believe that this experience is something that everyone should experience. It would be very beneficial to all. I think we should only be able to use disposable cameras instead of our phones. NO ELECTRONICS at all!

Yes. This experience opened my eyes more to see how difficult it is for us to live in a third world country. I thought that I could sort of relate to these people, but I was wrong. If I could go on this experience again I would in a heartbeat.

Yes. The experience makes you see that the U.S. has a better chance at everything. You also see the fact that students might come into your classroom hungry and tired. Their clothes might not look good and they might even smell.

Yes. I feel that having this experience was great for me. Growing up I was very sheltered and did not realize what people had to go through to just simply live. I [now] have a great understanding and will be able to show compassion for people in poverty.

Yes. One day when I become a teacher there may be a student or students in my class that don't have the proper resources at home that allow them 
to [be] resourceful in the classroom because they may have gone to bed the night before hungry or wasn't able to complete homework assignment [s] because they don't have power.

Yes. I think I very much enjoyed this trip. When we were going to meet custom [s], I knew that was fake and a situation drama. They wanted us [to] know about some of the customs that are rude and even not controlled by government. I am glad to live in the good relationship and kind country. For my travel experience, I haven't met this problem before putting me in the simulation. I am not angry and complaining. In this trip, we made in a group for seven people. I saw many different characteristics. Some of the classmates couldn't accept it and some of them were complaining. We made fires and cooked by ourselves. While facing these challenges, I saw many attitudes. You could participate or you rejected to help others. No one wants to be in bad life and poverty. Everyone has the responsibility to make life better.

Yes. This change has opened my eyes more than before because I was able to experience hard times. I was able to work hard to provide for my family. This trip inspired me to care more about the less fortunate people.

No. I have always had open eyes because of the way my family raised me. The experience has shown me to be a little more understanding. Everything is not given and when you work for what you have, you'll have more value for it. When my tribe family and I had to work together to start the fire and cook our food impacted my understanding of dispositions. We took nearly two hours to get the fire started. At that point we were desperate for food. Once we got the food done we were proud and did not focus on taste.

No. This trip allowed me to see how blessed I really am. I cannot fathom how people can live like that from day to day.

No. There were no changes. I have always thought the same about everyone. The thought of being able to be more grateful had an impact on my understanding for disposition.

No. I understand how people in other countries live. They are probably comfortable with their lifestyle. It was only hard for me because I was raised differently and if I was there alone I probably would've had a breakdown.

No. A person usually never thinks about other cultures and their environment until they walk in their shoes. Being in their places inspired me to want to learn more about them. I enjoyed the different houses, starting fires, and making my own food. It was an experience I wouldn't trade for the world. 
No. My thoughts did not change. I believe I was a good person before the trip.

No. To the best of my recollection I had no changes.

No. Not many of my answers changed, but the ones that did was because we as privileged people had to be thankful for what we have and need to help the ones who don't have much. I believe that the cultural immersion helped me realize that I am so glad I went in with an opened mindset so I could receive as much information as possible.

\section{Conclusion}

The researchers knew that the teacher candidates had a considerable amount of growing to do, as most of them did not have much exposure to cultures other than their own. Although this cultural immersion service learning experience was only a simulated environment, it was as close to reality as they would get in a limited space. The teacher candidates were at varied degrees when it came to recognizing their biases. Some admitted before the trip that they did not want to attend because they did not want to sleep outside. Others had no desire to go for an extended period of time without being able to take a shower. Both the sleeping arrangements and the availability to attend to matters of personal hygiene were directly related to the living conditions that residents face in countries around the globe. For students to express that they did not want to experience these "inconveniences," even for a short period of time, suggested either their lack of empathy for others or their lack of desire to be without their own comforts. What the researchers discovered is that the trip may not have completely changed the teacher candidates' dispositions. What it did accomplish was to give them an opportunity to try to begin to develop empathetic characteristics at most, and begin to be more appreciative of their blessings at the very least.

\section{References:}

1. Azano, A. P. \& Stewart, T. T. (2016). Confronting challenges at the intersection of rurality, place, and teacher preparation: Improving efforts in teacher education to staff rural schools. Global Education Review, 3(1), 108-128.

2. Bloom, Z. D., McNeil, V. A., Flasch, P., \& Sanders, F. (2018). A comparison of empathy and sympathy between counselors in training and their non-counseling academic peers. The Professional Counselor, 8(4), 341-354.

3. Bouton, B. (2016). Empathy research and teacher preparation: Benefits and obstacles. SRATE Journal, 25(2), 16-25. 
4. Choi, H., Benson, N.F., \& Shudak, N.J. (2016). Assessment of teacher candidate dispositions evidence of reliability and validity. Teacher Education Quarterly, 71-89.

5. Farnsworth, M. \& Mackenzie, J. Z. (2015). What inclusive dispositions contribute to culturally linguistically diverse exceptional students' success. International Journal of Special Education, 30(3), $52-70$.

6. Gutierrez, D. \& Gutierrez, A. (2019). Developing a trauma-informed lens in the college classroom and empowering students through building positive relationships. Contemporary Issues in Education Research, 12(1), 11-17.

7. Hoffman, M. (2001). Empathy and moral development: Implications for caring and justice. New York: Cambridge UP.

8. Honsinger, C. \& Brown, M. H. (2019). Preparing trauma-sensitive teachers: Strategies for teacher educators. Teacher Educators' Journal, $12,129-152$.

9. Immekus, J.C. (2016). The use of surveys in teacher education programs to meet accreditation standards: Preservice teachers' culturally responsive beliefs and practices. Research and Practice Assessment, 11, 18-28.

10. Jamili, L. B. \& Roshanzamir, Z. (2017). Postmodern feminism: Cultural trauma in construction of female identities in Virginia Woolf's The Waves. Advances in Language and Literary Studies, 8(4), 114-121.

11. Karges-Bone, L. \& Griffin, M. (2009). Do they have the right dispositions?: Teacher education in the new conceptual age. SRATE Journal, 18(2), 27-33.

12. Leake, E. (2016). Writing pedagogies of empathy: As rhetoric and disposition. Composition Forum, 34, 1-11.

13. Marchel, C.A. \& Shields, C. (2011). Preservice teachers as change agents: Going the extra mile in service-learning experiences. Teaching Educational Psychology 7(2), 3-16.

14. NCATE (2008) Retrieved from http://www.ncate.org/ /media/Files/caep/accreditationresources/ncate-standards-2008.pdf?la=en, 1-92.

15. Osler, J. E., \& Russell, S. (2013). An investigation on the impact of the socio-psychological effect of teacher disposition on the academic performance of students in a diversely populated elementary school. imanager's Journal on Educational Psychology, 7(1), 23-33.

16. Phipps, R. \& Thorne, S. (2019). Utilizing trauma-focused cognitive behavioral therapy as a framework for addressing cultural trauma in 
African American children and adolescents: A proposal. The Professional Counselor, 9(1), 35-50.

17. Shao, K. \& Tamashiro, R. (2013). Comparing teacher dispositions in China and the USA. Research in Higher Education Journal, 21, 1-7.

18. Stout, A. G. (2016). Perceptions of poverty and community action poverty simulation experience. Undergraduate thesis, under the direction of Eric Weber from Public Policy Leadership, University of Mississippi.

19. Venet, A. S. (2019). Role clarity and boundaries for trauma-informed teachers. Educational Considerations, 44(2), 2-9. 